\title{
MULHERES: HISTÓRIAS EM MOVIMENTO
}

\author{
WOMEN: STORIES IN MOVEMENT
}

\author{
Cleide Carvalho Matos ${ }^{1}$ \\ Ana D'Arc Martins Azevedo ${ }^{2}$ \\ Márcia Nemer Furtado ${ }^{3}$
}

\section{RESUMO}

Ao tratar do movimento das mulheres, o presente artigo tem como objetivo analisar o papel do movimento feminista nas sociedades contemporâneas. Do interior das lutas que deram materialidade ao movimento, examinamos o contexto histórico em que as mesmas ocorreram tendo em vista analisar a configuração do(s) movimento(s), seus impactos e consequências nas sociedades contemporâneas. Para a abordagem do tema realizamos uma pesquisa bibliográfica. Os resultados da pesquisa indicam que o movimento das mulheres possui, de um lado, características conservadoras e elitistas, mundialmente reconhecidas e, de outro, características de resistência das mulheres negras americanas cuja origem remonta à invisibilidade de classes.

Palavras-chaves: Mulheres; Resistência; Empoderamento.

\section{ABSTRACT}

This article aims to analyze the role of the feminist movement in contemporary societies through social movements. From inside of the struggles that gave materiality to the movement, we examine the historical context in which they occurred in view of analyzing the configuration of the movement(s), their impacts, and consequences in contemporary societies. To approach the theme, we conducted bibliographic research. The research results indicate that the women's movement has, on the one side, conservative and elitist characteristics, recognized worldwide and, on the other, aspects of resistance of black American women whose origin goes back to class invisibility.

Keywords: Women; Resistance; Empowerment.

\footnotetext{
1 Atualmente é Professora Adjunta II da UFPA Campus Marajó. Doutora em Educação - UFPA. e-mail: cleidematos@ufpa.br

2 Atualmente é Professora da UNMA e da UFPA. Doutora em Educação - UNMA. e-mail: azevedoanadarc@gmail.com

${ }^{3}$ Atualmente é Professora de Sociologia da Secretaria Estadual de Educação do Pará - SEDUC/PA. Mestrado em Gestão Pública - NAEA. e-mail: mnemerf@yahoo.com.br
} 


\title{
INTRODUÇÃO
}

\begin{abstract}
Uma noite, há anos, acordei bruscamente e uma estranha pergunta explodiu de minha boca. De que cor eram os olhos de minha mãe? [...] E quando, após longos dias de viagem para chegar à minha terra, pude contemplar extasiada os olhos de minha mãe, sabem o que vi? Sabem o que vi? Vi só lágrimas e lágrimas. Entretanto, ela sorria feliz. Mas eram tantas lágrimas, que eu me perguntei se minha mãe tinha olhos ou rios caudalosos sobre a face. E só então compreendi. Minha mãe trazia, serenamente em si, águas correntezas. Por isso, prantos e prantos a enfeitar o seu rosto. A cor dos olhos de minha mãe era cor de olhos d'água (EVARISTO, 2018, pp. 15; 19).
\end{abstract}

Olhos d'água é um conto que relata a vivência de sua autora, Conceição Evaristo, com sua mãe e seis irmãs. Já adulta, começou a se questionar o motivo de não lembrar a cor dos olhos de sua mãe. E o que mais a instigava era lembrar-se de seu silêncio diante das dificuldades, seus gestos de alegria, das suas histórias da infância, de detalhes de seu corpo e de como a mãe inventava brincadeiras para que Conceição e suas irmãs esquecessem-se da fome. Esquecera-se, entretanto, a cor dos olhos de sua mãe. O sentimento de culpa por tal esquecimento fez com que Evaristo deixasse tudo e voltasse ao local em que nascera para reencontrar sua mãe. Ao chegar, em meio ao sorriso de felicidade, viu só as lágrimas em seus olhos que, de tantas, mais pareciam um rio. Foi assim que se lembrou da cor dos olhos de sua mãe: cor de olhos d'água (GOMES, 2019).

Conceição Evaristo foi uma menina pobre, negra, criada em uma favela. Mais tarde, tornou-se professora e doutora em Literatura Comparada, sendo, hoje, um dos grandes expoentes da literatura brasileira, além de militante em defesa dos direitos dos negros, das mulheres e das populações marginalizadas. É exemplo do empoderamento das mulheres negras brasileiras que conseguiram sua liberdade criando formas de sobrevivência familiar diante da pobreza, da fome e de tantas outras dificuldades (GOMES, 2019).

As dificuldades enfrentadas pelas mulheres, ao longo da história das sociedades, apesar das particularidades - a exemplo das de Evaristo e milhões de mulheres - possuem um traço em comum: o despertar para as diversas formas de opressão e a vontade de lutar contra as mesmas. O que lhes é comum levou-as à constituição do movimento feminista que integra as organizações sociais de mulheres que lutam, principalmente, pelo direito à dignidade e à igualdade. Em virtude de tais especificidades, apresenta-se a seguinte problemática: qual a configuração, impacto e consequências do movimento feminista nas sociedades 
Revista

Debates Insubmissos

contemporâneas?

Para respondermos às questões propostas, realizamos uma pesquisa bibliográfica com a finalidade de analisar o papel do movimento feminista nas sociedades contemporâneas. De acordo com Lakatos e Marconi (2003, p. 183): “[...] a pesquisa bibliográfica não é mera repetição do que já foi dito ou escrito sobre certo assunto, mas propicia o exame de um tema sob novo enfoque ou abordagem, chegando a conclusões inovadoras”.

Para melhor analisar a materialidade da luta das mulheres, seus impactos e consequências para a sociedade contemporânea, a composição do artigo apresenta seis seções. Na primeira seção, Primeiros passos do movimento feminista no Brasil, relatamos os diferentes contextos e lutas das mulheres, principalmente, em torno do direito ao voto; na segunda seção, As lutas de mulheres durante o regime militar brasileiro, descrevemos a trajetória das lutas das mulheres que viveram em comum a inquietação relativa ao regime civil-militar brasileiro; na terceira seção, apresentamos o método utilizado para a realização da pesquisa; na quarta, $O$ feminismo enquanto movimento contestatório, abordamos o processo de vinculação do movimento a pautas mais específicas, tais como o processo de redemocratização no Brasil, direito reprodutivo e o combate à violência contra a mulher; na quinta seção, $O$ empoderamento das mulheres negras das américas, analisamos a criação de uma organização nacional de agremiações de mulheres negras e suas lutas em torno do empoderamento político-econômico para todas as mulheres. Por fim, na última seção, apresentamos as conclusões da pesquisa.

\section{PRIMEIROS PASSOS DO MOVIMENTO FEMINISTA NO BRASIL}

Ao pensarmos nos primeiros passos do movimento de mulheres não se pode deixar de mencionar a relação entre a mulher, a família e a estrutura social de modo a compreender, como afirma Gregori (2020, p. 49), que o feminismo é como se fosse uma arma para a "[...] desconstrução da estrutura patriarcal e de desigualdades que foram historicamente estabelecidas na sociedade". Tal desconstrução ataca a base das configurações da sociedade capitalista erguida na modernidade a partir das revoluções industriais.

Sob essa nova configuração, o homem deixou de exercer o papel do provedor passando 


\section{Revista \\ Debates Insubmissos}

a dividir tal função com as mulheres e as crianças que se tornam, para o dono dos meios de produção, uma engrenagem, uma peça a mais da máquina a serviço da ampliação do lucro. A peça sobressalente, apartada da cadeia produtiva até o surgimento da indústria, será representada pela possibilidade da exploração da mão de obra barata: das mulheres e crianças. Nesse contexto, o movimento feminista é como que um despertar para essa opressão: estamos, pois, diante dos primórdios de uma luta contra a desigualdade.

Ao tratarmos da sociedade brasileira, como a mulher adentra esse movimento sob o cenário de uma sociedade escravocrata?

Sabemos, conforme Teles (1999, apud SIMAS, 2019, pp. 10-11), que o movimento feminista só chega ao Brasil “[...] a partir da década de 1970, com destaque para o ano de 1975, considerado o ano internacional da mulher". Mas, bem antes dos anos de 1970, temos notícias dos crimes e transgressões praticados pelas mulheres negras escravas como meio de contestação do sistema escravista ${ }^{4}$.

Seus caminhos, na sociedade brasileira, conservarão a marca da sociedade escravista, ou da "cultura senhorial", conforme denominada por CFEMEA (2010, p. 110) "[...] a sociedade brasileira é marcada por uma estrutura hierárquica fortemente verticalizada" (CFEMEA, 2010, p. 110).

Sob a consigna movimento feminista, o mesmo surgirá no fim do século XVIII e início do século XIX, na maioria dos países europeus e nos Estados Unidos em um momento em que as mulheres passam a se dar conta da exploração sofrida e a se revoltarem contra o sistema opressor (GREGORI, 2000). Questionavam a jornada de trabalho mais longa e os salários menores comparativamente aos dos homens, além das péssimas condições de trabalho: ambientes insalubres e arriscados. Assim, a ordem até então estabelecida passou a ser subvertida. As mulheres avançam pelo mundo, com suas lutas políticas, lutas contra o sexismo e favoráveis à conquista dos direitos que lhes eram subtraídos.

Segundo Silva e Camurça (2010, apud GREGORI, 2020), as organizações feministas

\footnotetext{
${ }^{4}$ A esse respeito, referimos a leitura de Histórias de resistências de mulheres escravizadas em Pernambuco (18301856), de Tatiany de Oliveira Simas (2017).
} 


\section{Revista \\ Debates Insubmissos}

são orientadas pelos princípios da autonomia e da horizontalidade e "Por intermédio de diferentes repertórios de atuação, as feministas lutaram pela cidadania e pela vida de muitas mulheres abarcando pautas variadas". (GREGORI, 2020, p. 49). As pautas das lutas das mulheres voltavam-se, principalmente, ao direito à dignidade, à educação, à propriedade, à saúde, ao trabalho, ao voto e a não violência, injustiças e dominação. Todo esse processo em torno dos direitos sociais e políticos exige também novas condutas, práticas, conceitos e dinâmicas com relação às mulheres e ao movimento que as representa (GREGORI, 2020).

A partir das últimas décadas do século XIX, as mulheres começaram a se organizar em torno, principalmente, da luta pelo direito ao voto, por isso, o movimento foi denominado de "as sufragistas". Organizaram grandes manifestações, greves de fome, foram presas várias vezes. Mas o ápice desse primeiro momento foi quando "Em 1913, na famosa corrida de cavalo em Derby, a feminista Emily Davison atirou-se à frente do cavalo do Rei, morrendo. O direito ao voto foi conquistado no Reino Unido em 1918” (PINTO, 2020, p. 15).

O movimento se expandiu também para a América Latina envolvendo países como Argentina, Brasil, Chile, México, Peru e Costa Rica. No território brasileiro, por exemplo, a situação das mulheres também era difícil. Seguindo ordens da coroa portuguesa, a base de família patriarcal assegurava o poder do marido sobre a mulher, inclusive, do castigo físico, sendo seu papel o de mera reprodutora. As negras e escravizadas viviam situações ainda mais deterioradas: eram violentadas, oprimidas e exploradas, tanto pelo homem, quanto pela própria mulher branca (GREGORI, 2020).

Mesmo com as mais diversas formas de exploração, violência e desigualdade, as primeiras formas de luta do movimento feminista brasileiro serão, basicamente, relacionadas ao movimento abolicionista; em seguida, as operárias anarquistas reunirão costureiras, chapeleiras e classes anexas para denunciar a exploração sofrida nas fábricas e oficinas além da questão do voto. A questão do sufrágio universal é conhecida como a primeira onda do movimento feminista.

As sufragetes brasileiras foram lideradas por Bertha Lutz, bióloga, cientista de importância, que estudou no exterior e voltou para o Brasil na década de 1910, iniciando a luta pelo voto. Foi uma das fundadoras da Federação Brasileira pelo Progresso Feminino, organização que fez campanha pública pelo voto, tendo inclusive 


\section{Revista \\ Debates Insubmissos}

levado, em 1927, um abaixo-assinado ao Senado, pedindo a aprovação do Projeto de Lei, de autoria do Senador Juvenal Larmartine, que dava o direito de voto às mulheres. Este direito foi conquistado em 1932, quando foi promulgado o Novo Código Eleitoral brasileiro. (PINTO, 2020, p. 16).

Conforme a autora, o movimento feminista inicial - quer na Europa, Estados Unidos e mesmo no Brasil - perderá sua força a partir da década de 1930, reaparecendo na década de 1960 (PINTO, 2020, p. 16). Gregori (2020) reafirma tal proposição, ao alegar que, após a conquista do direito ao voto e, em seguida à participação no processo eleitoral, o movimento feminista, na Europa, na América e no Brasil, sofreu um período de desarticulação. Os direitos legais provocaram a desmobilizado não só do movimento das mulheres, mas também de vários movimentos sociais, como o movimento operário.

Somente entre 1943 e 1945, as mulheres saem novamente às ruas para apoiar a entrada do Brasil na guerra contra o totalitarismo nazifascista. Passando esse período, as organizações brasileiras e latino-americanas foram suprimidas. A situação se agrava após o golpe civil-militar de 1964, momento em que todos os movimentos populares foram submetidos ao silenciamento pela força da opressão estatal (PINTO, 2020).

Em desacordo com os movimentos feministas de resistência, as mulheres de extração social burguesa e das camadas médias da população apoiaram o golpe que instalou a ditadura brasileira, como atesta a famosa Marcha da Família com Deus pela Liberdade que une setores da Igreja, do empresariado e diferentes setores políticos contrários às reformas de base do governo de Goulart. Importa, no atual momento histórico brasileiro, rememorar que a referida Marcha foi organizada pela Tradição, Família e Propriedade (TFP), organização civil que, inspirada no catolicismo tradicionalista, foi fundada no Brasil, nos anos 1960, pelo deputado federal constituinte (em 1934) e católico Plinio Corrêa de Oliveira.

De outro lado, ao lembrarmos a participação das mulheres contra as forças políticas que, no Brasil, instituíram o governo militar, resgatamos a proposição de Pinto (2020, pp. 16-17):

Foi no ambiente do regime militar e muito limitado pelas condições que o país vivia na época, que aconteceram as primeiras manifestações feministas no Brasil na década de 1970. O regime militar via com grande desconfiança qualquer manifestação de feministas, por entendê-las como política e moralmente perigosas. Em 1975, na I Conferência Internacional da Mulher, no México, a Organização das Nações Unidas (ONU) declarou os próximos dez anos como a década da mulher. No Brasil, aconteceu, naquele ano, uma semana de debates sob o título 'O papel e o 


\section{nevistete

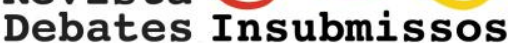

comportamento da mulher na realidade brasileira', com o patrocínio do Centro de Informações da ONU. No mesmo ano, Terezinha Zerbini lançou o Movimento Feminino pela Anistia, que terá papel muito relevante na luta pela anistia, que ocorreu em $1979^{5}$.

A organização das mulheres contra os regimes de exceção, como o vivenciado no Brasil no período da ditatura militar, revela a importância do movimento feminista na luta contra as opressões.

\section{AS LUTAS DE MULHERES DURANTE O REGIME MILITAR BRASILEIRO}

Na contramão do movimento das "feministas liberais", caracterizado, principalmente, por uma ideologia reformista, o movimento feminista socialista no Brasil volta-se às mudanças estruturais e às contradições fundamentais da organização social capitalista. Suas bases encontravam forças no movimento proletário internacional já espalhado por diversos países, com destaque para a Alemanha (GREGORI, 2020). Do interior desse paradigma (GREGORI, 2020, p. 56): “[...] as feministas firmavam participação em partidos comunistas e sindicatos de

forma coletiva e só tempos depois é que tentaram dar início, dentro dessas organizações, a grupos especificamente de mulheres", considerando que, em uma sociedade sem classes, não haveria desigualdades entre sexo, raça ou idade.

Rosa (2013) registra a trajetória das lutas de Nice Azevedo Cardoso, Yolanda Cerquinho

\footnotetext{
${ }^{5}$ Registramos, para historiar o momento vivido, a enorme quantidade de grupos feministas existentes no Brasil entre 1975 e 1985. "Certos grupos, mais ou menos informais, tiveram uma existência relativamente longa, outros adquiriram importância, mas foram efêmeros, outros ainda passaram por fracionamentos ou fusões, se transformaram e mudaram de denominação. Entre os que adquiriram visibilidade no Rio de Janeiro estão o Centro da Mulher Brasileira, o Coletivo de Mulheres, a Sociedade Brasil-Mulher, o Grupo Ceres, o Grupo Feminista do Rio de Janeiro; em São Paulo, o Brasil-Mulher, o Nós-Mulheres, a Associação das Mulheres, o Pró-Mulher, a Ação Lésbico-Feminista, a Frente de Mulheres Feministas, o Coletivo Feminista de Campinas, o Grupo Feminista 8 de Março, o Centro de Informação da Mulher. Nas regiões Nordeste e Norte cabe citar: em Salvador, BrasilMulher; em Pernambuco, o Ação-Mulher, a Casa da Mulher do Nordeste e o SOS Corpo de Recife; na Paraíba, o Centro da Mulher de João Pessoa; no Ceará, a União das Mulheres Cearenses e o Grupo Feminista 4 de Janeiro; no Maranhão, o Grupo de Mulheres da Ilha de São Luís; no Amazonas, a Casa da Mulher Universitária. Na região Sul pode-se mencionar: no Rio Grande do Sul, o Grupo de Mulheres de Porto Alegre Costela de Adão, o Movimento da Mulher pela Libertação, o Grupo Ação-Mulher, o Liberta; em Santa Catarina, o Amálgama e o Vivências; no Paraná, Brasil-Mulher, a Frente Democrática da Mulher Londrinense e o Movimento 8 de Março. Na região central tem-se em Minas Gerais, o Grupo de Reflexão Feminista e o Centro de Defesa dos Direitos da Mulher; em Goiânia, o Grupo Feminista de Estudos, o Centro de Valorização da Mulher, o Eva de Novo; em Mato Grosso, a Associação das Mulheres; em Brasília, o Grupo de Mulheres de Brasília, o Movimento de Emancipação da Mulher e Brasília-Mulher" (CPDOC, 2020).
} 


\section{novistet

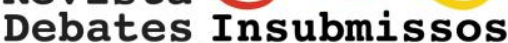

da Silva Prado (Danda Prado) e Flávia Schilling: mulheres que, embora não tenham se conhecido, partilharam a inquietação com o regime militar que perdurou no país entre os anos de 1964 a 1985. Foram mulheres que vivenciaram tempos difíceis, envolvendo ditadura, repressão, perseguição, exílio, tortura, pena de morte, assassinatos, para além do preconceito dos próprios sindicalistas socialistas. Nice Azevedo Cardoso, em meio a torturas e à destruição de seu corpo físico, encontrou na força emocional, advinda, principalmente, do desejo político de melhorar o mundo e nos afetos das amizades, a força para resistir e sobreviver. Yolanda Cerquinho da Silva Prado (Danda Prado), exilada e rompida com o Partido Comunista, passou a fazer parte do movimento feminista em Paris, o que, mais tarde, resultaria no movimento libertário brasileiro. Flávia Schilling, mesmo presa política no Uruguai por quase oito anos, manteve sua resistência revolucionária na prisão e, até hoje, luta contra a violência e a favor dos direitos humanos (ROSA, 2013).

Nessa época, a revolta frente às arbitrariedades sociais e os desejos de mudar o mundo e de derrubar a ditadura eram pontos comuns entre as mulheres. Entretanto, tiveram que enfrentar outra luta no interior dos movimentos dos quais participavam: a luta contra as diferenças de gênero. Na esquerda da época, a postura dominante era a de que as mulheres poderiam participar de suas organizações, mas não como dirigentes e nem estavam interessados nas questões femininas. Nesse sentido, puderam sentir as discriminações por parte de seus próprios companheiros de luta, que subestimavam suas capacidades (ROSA, 2013). Conforme Paradis (2020, p. 12):

Alexandra Kolontai (1872-1945) foi dirigente do Partido Comunista Russo e importante articuladora do movimento de mulheres trabalhadoras no seu país. Foi fundamental para reivindicar que as mulheres tivessem espaço no Partido e jogou luz sobre como a revolução bolchevique não poderia prescindir da igualdade entre homens e mulheres, sob o risco de fracassar. Suas críticas sobre os cursos da revolução, depois de 1918, vão fazer com que perca o posto de ministra e passe a ser embaixadora fora da Rússia. Conforme afirma De Miguel (1993), Kolontai foi marginalizada em primeiro lugar entre os dirigentes políticos marxistas do seu tempo e, em segundo, foi pouco reconhecida no próprio movimento feminista do século XXI.

A mesma concepção é reafirmada por (NYE apud ROSA 2013, p. 37):

Essa visão conservadora a respeito das mulheres dentro de movimentos comunistas e marxistas vem desde o século XIX [...]. O movimento sindicalista na França, [...] considerava as mulheres física, mental e moralmente inferiores [...], em 1866, a Associação Internacional dos Trabalhadores declarou o trabalho das mulheres como 
uma degeneração de raça, [...] em 1877, na Inglaterra, os mesmos princípios foram reafirmados. Na Alemanha, somente em 1900 foi permitido às mulheres filiarem-se ao partido socialista, entretanto, não podiam participar dos encontros mistos e mesmo assim, o marxismo parecia oferecer uma alternativa às feministas da época, [...].

Há muito, as mulheres de esquerda criticam tal concepção argumentando que a mesma fez com que o movimento socialista adotasse as teorias e práticas burguesas acerca da divisão dos papeis sociais, recusando-se a atender as especificidades das pautas femininas. Brasileiras feministas passaram a descortinar tal postura da esquerda e a cobrar uma atitude diferente (ROSA, 2013). Entretanto, os relatos de grande parte de mulheres de luta no Brasil atestam que, ao participarem das organizações contra a ditadura, tiveram que adotar um modelo masculino de militância, transformando-se apenas em um sujeito universal masculino sob a justificativa de que precisavam se aproximar das classes populares em prol da revolução proletária. $\mathrm{Na}$ verdade, desconsideravam a presença feminina impelindo-a à invisibilidade. Essas posturas, tradicionais e machistas, levariam muitas militantes a tornarem-se feministas de esquerda (ROSA, 2013).

O momento mais conturbado do período militar foi a partir do "Ato Institucional de número 5 e os outros decretos que se seguiram como AI-14, que legitimou a pena de morte e a prisão perpétua no país [...]" (ROSA, 2013, p. 48). Para manter-se na luta política, a experiência da clandestinidade fez parte da experiência de Nice Cardoso, como da de tantas outras mulheres. As privações emocionais e físicas eram novas formas de invisibilidade. Pior do que a clandestinidade, só a violência durante a tortura. Reduzir a mulher à nudez era o primeiro passo dos torturadores. Na sala de tortura, os policiais iniciavam as agressões verbais, psicológicas e físicas. As mulheres eram agredidas duplamente: por serem militantes e por serem mulheres. De acordo com relatos das próprias vítimas, em documentários como "Memórias para uso diário", Rosa (2013, p. 459) acrescenta “[...] que quase todas foram estupradas. Embora a nudez e a tortura nos órgãos genitais fossem constantes para homens e mulheres no momento da tortura, o estupro é utilizado especificamente contra mulheres".

No relato de Nice Cardoso, a tortura leva, para além da dor física, à dor na alma, pois era como se tivesse que suportar o insuportável. Nada que ouvira nos relatos comparava-se ao vivido. O choque elétrico externo e interno era acompanhado de violências físicas e 
depreciações. Os sentimentos se misturavam à impotência e tornava-se, ao mesmo tempo, a força capaz de libertar, resistir e reencontrar a vida (ROSA, 2013):

Relatos que não se restringem aos regimes ditatoriais ou de décadas passadas, são nossos contemporâneos, basta nos determos um pouco ao Relatório da Anistia: situação das mulheres no Afeganistão, estupros generalizados no Sudão, situação semelhante no Congo e na Colômbia, violações constantes nos acampamentos para refugiados, entre muitos outros e sem contar a violência cotidiana, em casa, na rua, no trabalho. (ROSA, 2013, p. 67).

A ditadura, assim como as novas formas de tortura, não só fomenta a angústia, mas reprime os torturados a ponto de chegarem ao limite que se encerra com o suicídio, ou com a superação. As memórias testemunham que a escolha pela vida depende de amizades, da vontade de continuar contribuindo com um mundo melhor, do equilíbrio entre a recordação e a necessidade de superação. Precisamos repensar essas experiências de forma a torná-las a razão da resistência, da luta por direito e justiça (ROSA, 2013).

\section{METODOLOGIA}

O delineamento do percurso metodológico desta pesquisa passou pela definição da concepção de história norteadora desta investigação haja vista a opção por uma escola histórica implicar assumir uma postura epistemológica que permita ao pesquisador lidar com o seu objeto de estudo de forma coerente; todavia, tal postura não pode configurar-se como uma camisa de forças que impeça o trânsito por outros constructos que auxiliem o esclarecimento dos problemas de pesquisa.

Na perspectiva da história tradicional, há uma valorização dos grandes feitos, dos acontecimentos políticos e militares, valorização do sujeito individual. O pesquisar na

[...] a história tradicional enfatizava a 'história acontecimental': o homem aparecia na história política, das ideias, na biografia dos grandes líderes. A história tradicional era um 'olhar a partir de cima': psicológica, elitista, biográfica, qualitativa, visava o particular, o individual e o singular, era legitimadora, partidária, comemorativa, uma narrativa justificadora do poder presente (REIS, 2010, p. 40).

Nesta perspectiva, a pesquisa histórica tradicional pauta-se no paradigma positivista de ciência, no qual o método científico é o principal meio para se chegar à verdade dos fatos, nesse caso, a verdade histórica. O tempo histórico é concebido como uma sequência de fatos lineares, 
de acontecimentos políticos. Todavia, ao "[...] incorporar a consideração da simultaneidade, que é a dominação da assimetria entre passado e futuro, a história tornou-se outra que a tradicional. Ela mudou seus objetos, seus historiadores e seus objetivos [...]” (REIS, 2010, p. 39) e, da mesma forma, mudaram os problemas de pesquisa.

Nesse sentido, Lombardi (2004, p. 157) ao se referir às transformações no campo da historiografia, afirma: “[...] Com Engels e Marx, e depois com Febvre e Bloch, aprendemos que a vida de todos os homens, todas as formas de relações, todos os agrupamentos e classes sociais constituem objetos de estudo que interessam ao investigador".

O movimento de renovação da historiografia, sobretudo a partir da escola dos Annales, ampliou o campo de estudo do historiador, permitindo ultrapassar fronteiras entre as diversas áreas do conhecimento, principalmente entre a história e as ciências sociais. O historiador passou a dispor [...] "de um tempo novo, elevado à altura de uma explicação, em que a história se pode inscrever, recortando-se, segundo pontos de referências inéditos, segundo curvas e a sua própria respiração" (BRAUDEL, 1972, p. 18). A nova perspectiva se manifesta nos trabalhos realizados pelos historiadores ligados ao movimento dos Annales, sobretudo nas pesquisas acadêmicas. Para Luca (2008, p. 113)

A face mais evidente do processo de alargamento do campo de preocupação dos historiadores foi a renovação temática, imediatamente perceptível pelo título das pesquisas, que incluíam o inconsciente, o mito, as mentalidades, as práticas culinárias, o corpo, as festas, os filmes, os jovens e as crianças, as mulheres, aspectos do cotidiano, enfim uma miríade de questões antes ausentes do território da história.

Esse gotejamento de novas temáticas, objetos e abordagens evidenciam a efervescência de uma nova maneira de pensar e fazer pesquisa acadêmica. Do mesmo modo, as relações estabelecidas entre as diversas áreas do conhecimento alargam as possibilidades de análise do objeto, permitindo ao pesquisador passear por campos antes considerados exclusivos de geógrafos, antropólogos e historiadores de profissão.

De acordo com Burke (2010, p. 7)

Se a história, como sempre pretendeu Febvre, era filha de seu tempo, não seria possível continuar a fazer esse tipo de história convencional que nem correspondia aos anseios de uma humanidade que vivia, nessas décadas, momento de convulsões e rupturas com o passado, nem conseguia responder satisfatoriamente às exigências do novo homem que daí surgia. 
Na perspectiva dos Annales, os historiadores passaram a dar mais ênfase ao não acontecimental, ao mundo mais durável, mais resistente a mudanças, a vida econômica, social, material e mental (REIS, 2010). A historiografia, a partir da noção de tempo estrutural ${ }^{6}$ e conjuntural $^{7}$ aliado ao conceito de espaço revolucionou a pesquisa historiográfica. Para Braudel (1972, p. 29) "Cada atualidade reúne movimentos de origem e de ritmo diferente: o tempo de hoje data simultaneamente de ontem, de anteontem, de antanho". Portanto, o tempo tem diferentes temporalidades, ritmos e movimentos. Por isso, o trabalho histórico é um trabalho crítico por excelência (BRAUDEL, 1972, p. 92).

Por seu turno, a historiografia da educação mantém a sua relação com as perspectivas teórico-epistemológicas das pesquisas históricas, porém seu objeto de investigação, segundo Lombardi (2004), são as produções históricas que estudam a educação:

\begin{abstract}
Apesar de ser um campo recente, a historiografia da educação praticamente reproduziu as características da produção historiográfica, com trabalhos em que a produção no campo da história da educação é de caráter descritivo, com ênfase nos aspectos formais da produção (tema, período, fontes, etc.); mas também possuindo alguns trabalhos que fazem uma análise dessa mesma produção a partir de seus pressupostos metodológicos e teóricos (LOMBARDI, 2004, p. 153).
\end{abstract}

A pesquisa histórica, segundo Lombardi (2004), tem se beneficiado das tecnologias da informação e comunicação,

Esses novos instrumentos tornaram possível a rápida consulta a sofisticados bancos de dados de bibliotecas, arquivos e centros de documentação de todo mundo. Para além da mera consulta, também é possível acessar (via internet) uma grande quantidade de fontes (documentais, iconográficas, audiovisuais etc.) disponibilizado por fidedignas instituições depositárias [...]. (LOMBARDI, 2004, p. 159).

Nesta pesquisa utilizamos a pesquisa bibliográfica haja vista termos considerado a pertinência da mesma para responder à questão problema formulada no âmbito desta pesquisa. Para Severino (2007, p. 122), a pesquisa bibliográfica é fundamental para compreendermos o universo pesquisado, pois “[...] se realiza a partir do registro disponível, decorrente de pesquisas

\footnotetext{
${ }^{6}$ Chaunu definiu esse vocábulo como "[...] tudo que numa sociedade, ou numa economia, tem uma duração suficientemente longa em sua modificação para escapar ao observador comum" (1959, p. 12 apud BURKE, 2010, p. 146).

${ }^{7}$ Este vocábulo, segundo Burke (2010), foi adotado pelos historiadores dos Annales, no sentido oposto ao da estrutura, referindo-se a curta e a média duração.
} 
anteriores, em documentos impressos, como livros, artigos, teses, etc." Permite, ainda, ao pesquisador, o contato com tudo o que foi escrito e teorizado sobre o seu tema de pesquisa (PÁDUA, 2004), oferecendo meios para (re)definirmos o encaminhamento da pesquisa.

É com base nesse conhecimento acumulado pelas pesquisas anteriores que podemos apresentar os avanços, as lacunas e as fragilidades na produção do conhecimento científico, dentro de um determinado campo do saber. Do mesmo modo, encontrar as pistas para traçarmos novas rotas, caminhos ou trajetórias visando o desenvolvimento de novas investigações.

\section{O FEMINISMO ENQUANTO MOVIMENTO CONTESTATÓRIO}

Em meados da década de 1970, o movimento feminista na Europa e em países como o Brasil reaviva-se novamente, agora com características contestatórias por não aceitar mais o atrelamento ao movimento operário e às lutas gerais. É um momento de muitas divergências internas, principalmente, entre as tendências partidárias e as correntes autônomas. Conforme Gregori (2020), a proposta era a de passar a ser diferente e não mais subordinado a outro movimento qualquer (GREGORI, 2020).

Com o estabelecimento da nova ordem capitalista, que ampliou o campo de atuação da mão de obra feminina, demandando maior formação educacional, podemos denominar esse novo contexto do movimento das mulheres de "feminismo contemporâneo" enquadrando-se nos novos movimentos sociais. Neste contexto, a luta era, principalmente, contra o sexismo e, no caso brasileiro, em favor também do processo de redemocratização, direito reprodutivo e combate à violência contra a mulher (GREGORI, 2020).

Apesar de todas essas lutas, o movimento feminista só conseguiu se institucionalizar a partir da Constituição federal de 1988, o que era ao mesmo tempo contraditório, pois quem sempre oprimiu e omitiu os direitos das mulheres reconhecia, agora, oficialmente, suas lutas. A esperança era que a institucionalização trouxesse mudanças significativas à relação com o estado e com a sociedade, pois essa articulação aliada à organização do movimento poderia representar maior pressão sobre políticas sociais estatais que garantissem igualdade de gênero (GREGORI, 2020). 
Revista

Debates Insubmissos

Nessa perspectiva, o movimento feminista assume uma postura mais propositiva e intervencionista uma vez que a institucionalização possibilitava maior participação nos processos de elaboração e execução de políticas públicas. Entretanto, a década de 1990 presencia também o financiamento do movimento por organismos internacionais e a criação de organizações não governamentais (ONGs) gerando um número muito grande de organização de mulheres. Por outro lado, vivencia-se uma crescente perda de autonomia e da força transformadora do movimento (GREGORI, 2020).

Vale enfatizar que, para além da diversidade de organizações, o movimento feminista ainda possui posicionamentos políticos distintos relativamente à teoria de classes e à teoria da diversidade de gênero, o que provoca contradições em suas bandeiras de luta. Ainda não há consenso, por exemplo, em relação à inserção, nas pautas do movimento, de questões relativas ao movimento LGBT, transfeministas, racismo, entre outras (GREGORI, 2020). Nesse sentido, lemos em Ferreira e Aguinsky (2020, p. 224):

Não é da atualidade que os temas da sexualidade e do gênero são invisibilizados pelos campos políticos, sociais e também acadêmicos (BENTO, 2006), mesmo tendo ganhado centralidade em diferentes áreas do saber com o surgimento do movimento feminista e LGBT - no Brasil, mais profundamente na década de 1980 (GREEN, 2000; LOURO, 1997). Contraditoriamente, diferentes instituições ideológicas, tais como a família, a religião, a medicina, o sistema escolar, de justiça, de segurança, entre outras, constroem significados sobre a sexualidade e o gênero (FOUCAULT, 1988) ditando modelos de normalidade e de comportamento, produzindo saberes de controle sobre corpos e desejos.

O cenário atual de política neoliberal e desmonte estatal brasileiro também poderá provocar novas alterações nos objetivos dos movimentos sociais, incluindo o feminista, pois com as várias medidas antidemocráticas de desmonte de políticas públicas, a exemplo da Emenda Constitucional 95/2016, que prevê o congelamento dos gastos públicos por vinte anos, além das reformas previdenciária e trabalhista, as demandas de lutas das mulheres serão, com certeza, abaladas (GREGORI, 2020).

Com a extrema direita no poder, a criminalização dos movimentos sociais, incluído aí o das mulheres, a situação se agrava. Diferentes formas de violência, por meio de atos racistas, homofóbicos, feminicídio que deveriam ter cessado no século XXI, alcançam números assustadores: 
Discursos de ódio social alimentam o cerceamento da pobreza, da questão de gênero, raça, das liberdades políticas e religiosas, criando contornos dramáticos para a situação brasileira. Soluções violentas e antidemocráticas são cada vez mais acentuadas (GREGORI, 2020, p. 64).

Ao mencionarmos as diferentes formas de violência às quais as mulheres encontram-se historicamente submetidas, não se pode deixar de lado a importância de tocar a questão da mulher negra, pois,

\begin{abstract}
As discriminações de raça e gênero produzem efeitos imbricados, ainda que diversos, promovendo experiências distintas na condição de classe e, no caso, na vivência da pobreza, a influenciar seus preditores e, consequentemente, suas estratégias de superação. Neste sentido, são as mulheres negras que vivenciam estas duas experiências, aquelas sempre identificadas como ocupantes permanentes da base da hierarquia social (SILVA, 2013, p.1, apud ASSIS, 2020, p. 5).
\end{abstract}

Daí a importância de tratarmos a questão do empoderamento das mulheres negra na próxima seção.

\title{
6. O EMPODERAMENTO DAS MULHERES NEGRAS DAS AMÉRICAS
}

Segundo Silva (2017), o termo empoderamento possui diferentes significados. Entre eles, o poder, a liberdade e a informação que permitem a tomada de decisões e a participação ativa da comunidade. Ganha força nos movimentos emancipatórios surgidos nos anos de 1960, nos Estados Unidos, mas é somente na década de 1970 que o empoderamento é associado aos processos de conquista de direitos à cidadania ${ }^{8}$.

O empoderamento das mulheres negras norte-americanas se constituiu, principalmente, a partir de 1895, momento em que estas foram repelidas pelo próprio movimento feminista por mulheres brancas de classe média. Nesse contexto, “[...] cem mulheres negras de dez estados se reuniram na cidade de Boston, sob a liderança de Josephine St. Pierre Ruffin, para discutir a criação de uma organização nacional de agremiações de mulheres negras" (DAVIS, 2019, p. 16). Suas lutas tiveram como base o desenvolvimento de estratégias para alcançar o poder político-econômico para todas as mulheres e a defesa ideológica e militante contra o racismo,

\footnotetext{
${ }^{8}$ Sobre empoderamento ler: CORNWALL, Andrea. Além do "Empoderamento Light": empoderamento feminino, desenvolvimento neoliberal e justiça global. Cadernos Pagu n. 05, v. 52, pp. 1-33, 2018. Disponível em: https://www.scielo.br/pdf/cpa/n52/1809-4449-cpa-18094449201800520002.pdf
} 


\section{Revista \\ Debates Insubmissos}

independente de sexo, ou seja, uma luta pelo bem comum de toda humanidade.

Em 1896, foi anunciada a criação da Associação Nacional das Agremiações das mulheres de cor. Uma das principais preocupações da associação era a conquista do direito ao voto, pois mesmo que tivessem consciência de que essa conquista não significaria emancipação, tinham certeza de que esse era o caminho para salários mais justos, melhores condições de trabalho. O lema da associação era "erguendo-nos enquanto subimos", que significava a ajuda mútua entre mulheres e homens de todas as origens sociais em torno da luta geral contra todos os tipos de desigualdades e invisibilidades (DAVIS, 2019). Nesse caminho:

Milhões de mulheres estão hoje preocupadas com emprego, condições de trabalho, salários mais altos e violência racista. Elas estão preocupadas com o fechamento de fábricas, com falta de moradia e com a legislação migratória repressiva. Estão preocupadas com a homofobia, o idadismo e a discriminação contra pessoas com deficiências físicas. Estamos preocupadas com a Nicarágua e a África do Sul. E compartilhamos com nossas crianças o sonho de que o mundo de amanhã esteja livre da ameaça de um onicídio nuclear. (DAVIS, 2019, p. 17).

No século XXI, o empoderamento das mulheres negras norte-americanas se estende àquelas que descendem da invisibilidade de classes - negras, latinas indígenas, asiáticas e brancas da classe trabalhadora. Por outro lado, temos o movimento de mulheres reconhecido mundialmente - brancas, dominantes, classe média. Deveria ser difundido um coletivo único, que lutasse por todas as mulheres, independente de classe ou etnias, contra toda forma de exclusão (DAVIS, 2019).

Na América Latina, as desigualdades raciais, étnicas e de gênero constituem uma lacuna estrutural que determina desvantagens comparativamente a outros espaços territoriais. Por isso, a articulação da mulher negra na América Latina e Caribe, em torno dessa luta afirmativa, cresce e ganha forma, principalmente a partir dos primeiros encontros feministas negros e latino-americanos nas décadas de 1980 e 1990.

As mulheres negras latino-americanas e caribenhas, silenciadas pelo movimento feminista europeu e norte-americano, articularam-se regionalmente em busca de suas demandas e na consolidação da agenda das conferências mundiais das Nações Unidas. Em consequência dessas articulações foi criada a Rede de Mulheres Afro-latino-americanas, Afro-caribenhas e da Diáspora, que constitui importante rede de organização de mulheres negras na América 
Latina e Caribe. Nesse contexto, as mulheres negras brasileiras também demarcaram um protagonismo nas esferas nacional, regional e mundial.

Nessa perspectiva, o processo de empoderamento é uma forma de resistência organizada que vai além dos interesses de sexo, envolvendo lutas contra toda forma de opressão ou exploração. É um ativismo político que expressa a compreensão de que as diversas relações extremas de violência como a homofobia e o sexismo estão relacionadas ao racismo. Por isso, se reconhece que o empoderamento das mulheres só será realmente alcançado quanto tivermos êxito na luta contra o racismo (DAVIS, 2019, p. 29):

Estamos vivendo em uma era de profunda crise global do capitalismo monopolista, uma época de riscos crescentes de um onicídio nuclear, uma época de ameaça de invasão da América Central pelos Estados Unidos e um período em que a iminência do fascismo traz perigo sem precedentes. $O$ movimento de mulheres não pode pagar o preço de repetir erros do século passado ou mesmo da década passada. Equívocos e omissões - particularmente aquelas que podem ser atribuídas ao racismo - devem ser imediatamente examinados, e medidas devem ser tomadas para corrigi-los.

As mulheres negras americanas sempre foram mais impactadas pelas desigualdades econômicas, políticas e sociais do que as brancas. Às adolescentes negras, por exemplo, são negadas as oportunidades de educação, lazer, creches, assistência à saúde, empregos significativos e bem remunerados. Por esses fatores, um dos maiores desafios desse movimento é o de criar estratégias de enfrentamento às agressões ideológicas e materiais provenientes da opressão econômica, racial e sexual nas conjunturas do racismo (DAVIS, 2019).

Outro forte ponto da luta está relacionado à violência sexual contra as mulheres, que começou a ganhar forma durante os primeiros anos da década de 1970. O movimento antiestupro, por exemplo, contestou principalmente o mito de que "a vítima de estrupo é moralmente responsável pelo crime cometido contra ela" (DAVIS, 2019, p. 44). Esse é um crime cometido com mulheres de todas as raças ou classes sociais. Outro mito combatido é o de que a maioria dos estupros é praticada por homens negros, mostrando como o racismo está impregnado nas mais diversas posturas sociais.

Geralmente, a violência sexual emana da própria política oficial e de estruturas de poder. No contexto de ditaduras fascistas, por exemplo, mulheres prisioneiras políticas, foram espancadas, torturadas, estupradas coletivamente. Muitas forças policiais, que alegam o 
combate à violência sexual, têm como objetivo velado a repressão racista. São relações “[...] complexas que refletem a interligação da opressão de raças, gênero e classes mediadas pela violência e poder raciais, classistas e governamentais" (DAVIS, 2019, p. 49).

O estupro torna-se apenas uma dentre as várias formas de opressão das mulheres, portanto, a resistência precisa combater também as violências racistas, sexistas, antissemita, nazista, fascista. Lutar pela libertação de prisioneiros políticos, pelas revoluções democráticas e consequentemente, "criar uma nova e revolucionária ordem global, em que toda forma de opressão e violência contra a humanidade seja obliterada" (DAVIS, 2019, p. 52).

\section{CONCLUSÕES}

Os resultados do presente estudo indicam que o primeiro momento do movimento feminista brasileiro foi marcado, principalmente, por características ditas conservadoras ${ }^{9}$, na medida em que não questionava a estrutura da sociedade capitalista, as desigualdades sociais, a pauta de reivindicação girava em torno da luta pelo voto, por melhores condições de trabalho e salários dentro das fábricas, ou seja, não vislumbrava a superação da exploração da força de trabalho feminina. No Brasil, com exceção da luta pela abolição da escravatura, a luta das mulheres também teve seu cunho liberal, expresso, principalmente, pelo apoio das mulheres de classe média à ditatura militar, ao modelo de desenvolvimento social pautado nos ideais do liberalismo. Em contraposição, mulheres envolvidas com o movimento operário, de ideais socialistas, demonstravam caminhar em direção contrária ao capitalismo e aos governos ditatoriais. No Brasil, por exemplo, muitas delas se submeteram à invisibilidade da militância, além das perseguições e torturas em prol da luta por um mundo melhor. As memórias dessas mulheres testemunharam experiências de dor, sofrimento, mas, igualmente, de transformação dessas lembranças na razão da resistência, da luta por direito e justiça.

As mulheres negras americanas - que sempre foram mais impactadas pelas

\footnotetext{
${ }^{9}$ Para uma leitura mais específica sobre conservadorismo e liberalismo ver: DOMBROWSKI, O. Conservador nos costumes e liberal na economia: liberdade, igualdade e democracia em Burke, Oakeshott e Hayek. Rev. Katálysis, Florianópolis, v. 23, n. 2, p. 223-234, maio/ago. 2020. Disponível em: https://www.scielo.br/pdf/rk/v23n2/1982-0259-rk-23-02-223.pdf.
} 
desigualdades econômicas, políticas e sociais do que as mulheres brancas - além de serem excluídas pelo movimento geral motivos pelos quais organizaram suas lutas, principalmente, em torno da ajuda mútua entre mulheres e homens de todas as origens sociais em prol da luta contra todos os tipos de desigualdades e invisibilidades.

Assim, em resposta à problemática acerca da configuração, impacto e consequências do movimento feminista nas sociedades contemporâneas - em que pesem as características politicamente contraditórias do movimento - pode-se afirmar que o mesmo impôs e continua impondo à sociedade diferentes formas de descortinar a invisibilidade da mulher, bem como a estrutura classista da sociedade brasileira.

O impacto de desses movimentos sobre a sociedade relaciona-se, principalmente, aos direitos conquistados: o direito ao voto, à participação política, à participação na Anistia Internacional, à institucionalidade do movimento. A distinção do movimento recai sobre a visibilidade de seus princípios - da autonomia e da horizontalidade - e das pautas sempre atualizadas, a exemplo do direito à dignidade, educação, propriedade, saúde, trabalho e a recusa à violência, injustiças e dominação.

Por fim - mesmo com a permanência das mais diversas formas de exploração, violência e desigualdade, memórias de tempos difíceis, envolvendo ditadura, repressão, perseguição, exílio, tortura, pena de morte, assassinatos, preconceitos - a maior consequência do movimento para as sociedades contemporâneas é que muitas mulheres encontram, na luta de umas e outras, bem como de umas pelas outras, a esperança, a força, o empoderamento e a razão para continuar resistindo contra o racismo, a intolerância e a invisibilidade ante o feminicídio, o estupro, o abuso e a exploração sexual, dentre tantas outras formas de opressão.

\section{REFERÊNCIAS}

ASSIS, Camila Vieira da Silva de. Mulheres negras, opressões, feminismo negro e entretenimento. In: VI SEMINÁRIO CETROS: Crise e mundo do trabalho no Brasil: desafios para a classe trabalhadora. UECE, 2018. Disponível em: http://www.uece.br/eventos/seminariocetros/anais/trabalhos_completos/425-5124215072018-114301.pdf. Acesso em: 02 Jul. 2020. 
BRAUDEL, Fernand. História e ciências sociais. Tradução de Carlos Braga \& Inácia Canelas. Santos, SP: Editora Presença, 1972.

BURKE, Peter. A escola dos Annales 1929 - 1989: a revolução francesa da historiografia. $2^{\mathrm{a}}$ ed. São Paulo, UNESP, 2010

CENTRO FEMINISTA DE ESTUDOS E ASSESSORIA (CFEMEA). BRAZÃO, Analba; OLIVEIRA, Guacira Cesar de (Orgs.). Violência contra as mulheres - Uma história contada em décadas de lutas. Brasília: CFEMEA: MDG3 Fund., 2010.128p. (Coleção 20 anos de cidadania e feminismo; 6)

DAVIS, Angela. Mulheres, cultura e política. Tradução Heci Regina Cadiani. $1^{\text {a }}$ ed., São Paulo. Boitempo, 2017.

EVARISTO, Conceição. Olhos d'água. 2. ed. Rio de Janeiro, RJ: Pallas Míni, 2018.

FERREIRA, Guilherme Gomes; AGUINSKY, Beatriz Gershenson. Movimentos sociais de sexualidade e gênero: análise do acesso às políticas públicas. Rev. Katálysis, Florianópolis, v. 16, n. 2, p. 223-232, Jul./Dez. 2013. Disponível em:

https://www.scielo.br/pdf/rk/v16n2/08.pdf. Acesso em: 20 Jun. 2020.

GOMES, Heloisa Toller. Prefácio. In: EVARISTO, Conceição. Olhos d'água. 2. ed. Rio de Janeiro, RJ: Pallas Míni, 2018.

GREGORI, Juciane de. Feminismos e resistência: trajetória histórica da luta política para conquista de direitos. Caderno Espaço Feminino. Uberlândia-MG - v. 30, n. 2, Jul./Dez. 2017. Disponível em: http://www.seer.ufu.br/index.php/neguem/article/view/38949. Acesso em: 12 Ago. 2020.

LAKATOS, E. M.; Marconi; M. de A. Fundamentos de metodologia científica. 5. ed., São Paulo: Atlas, 2003.

LIMA, Emanuel Fonseca et. al. Ensaios sobre racismos: pensamento de fronteiras. 2020. Disponível em: https://ocarete.org.br/wpcontent/uploads/2020/05/ensaios_sobre_racismos_novo.pdf. Acesso em: 12 Jan. 2021.

LOMBARDI, José Claudinei. História e historiografia da educação: atendendo para as fontes. In: LOMBARDI, José Claudinei; NASCIMENTO, Isabel Moura (Orgs). Fontes, história e historiografia da educação. Campinas, SP: Autores Associados: HISTEDBR; Curitiba, PR: Pontifícia Universidade Católica do Paraná (PUCPR); Palmas, PR: Centro Universitário Diocesano do Sudoeste do Paraná (UNICS); Ponta Grossa, PR: Universidade Estadual de Ponta Grossa (UEPG), 2004.

LUCA, Tania Regina de. História dos, nós e por meio dos periódicos. In: PINSKY, Carla Bassanezi; LUCA, Tania Regina de (org.). Fontes históricas. 2. ed., $1^{\text {a }}$ reimpressão. São Paulo: Contexto, 2008. (111-153).

MOVIMENTO FEMINISTA (verbete). In: Centro de Pesquisa e Documentação de História Contemporânea do Brasil (CPDOC). Rio de Janeiro: RJ: FGV, 1983. Disponível em: http://www.fgv.br/cpdoc/acervo/dicionarios/verbete-tematico/movimento-feminista. Acesso em: 20 Jun. 2020. 
PÁDUA, Elisabete Matallo Marchesini de. Metodologia de pesquisa: abordagem teóricoprática. 13 $3^{a}$ ed. Campinas, SP: Papirus, 2004 (Magistério: Formação e Trabalho Pedagógico, v. XX).

PARADIS, Clarisse Goulart. A prostituição no marxismo clássico: crítica ao capitalismo e à dupla moral burguesa. Revista Estudos Feministas, Florianópolis, 26(3): e44805. Disponível em: https://www.scielo.br/pdf/ref/v26n3/1806-9584-ref-26-03-e44805.pdf. Acesso em 12 Mar. 2020.

PINTO, Céli Regina Jardim. Feminismo, História e Poder. Revista de Sociologia e Política. Curitiba, v. 18, n. 36, p. 15-23, jun. 2010. Disponível em:

https://www.scielo.br/pdf/rsocp/v18n36/03.pdf. Acesso em: 20 Jun. 2020.

REIS, José Carlos. Os Annales: a renovação teórico-metodológica e utópica da história pela reconstrução do tempo histórico. In: SAVIANI, Dermeval; LOMBARDI, José Claudinei; SANFELICE, José Luiz. História e história da educação: o debate teóricometodológico atual. $4^{\mathrm{a}}$ ed. Campinas, SP: Autores Associados: HISTEDBR, 2010.

ROSA, Susel Oliveira da. Mulheres, ditaduras e memórias: Não imagine que precise ser triste para ser militante. São Paulo: Intermeios, FAPESP, 2013.

SEVERINO, Antônio Joaquim. Metodologia do trabalho científico. 23a ed. São Paulo: Cortez, 2007.

SILVA, Kelly Cristina da. Os letramentos de empoderamento feminino negro: a educação de jovens e adultos e os processos de aprendizados na rede social facebook. Dissertação de Mestrado. FAE/UFMG, como Belo Horizonte, 2017. Disponível em https://repositorio.ufmg.br/bitstream/1843/BUOS ARJGDH/1/kellycs_disserta_o_final_iii.pdf. Acesso em: 12 Jan. 2021.

SIMAS, Tatiany de Oliveira. Histórias de resistências de mulheres escravizadas em Pernambuco (1830-1856). Dissertação de Mestrado. História, UFPB, 2017. Disponível em https://repositorio.ufpb.br/jspui/bitstream/123456789/11957/1/Arquivototal.pdf. Acesso em: 20 Jun. 2020.

Submetido em: 16/10/2020

Aprovado em: 02/03/2021 